\title{
Influence of remaining tooth substance and post-endodontic restoration on fracture strength of endodontically treated maxillary incisors
}

\author{
Valentina SPICCIARELLI' ${ }^{1}$ Crystal MARRUGANTI², Ilaria FEDELE ${ }^{1}$, Marco MARTIGNONI' ${ }^{1}$ Hani OUNSI ${ }^{3}$, \\ Marco FERRARI ${ }^{4}$ and Simone GRANDINI ${ }^{1}$ \\ ${ }^{1}$ Department of Medical Biotechnologies, Unit of Endodontics and Restorative Dentistry, University of Siena, Viale Bracci 16, Siena, Italy \\ ${ }^{2}$ Undergraduate Program in Dentistry, University of Siena, Viale Bracci 16, Siena, Italy \\ ${ }^{3}$ Department of Restorative Dentistry and Endodontics, Faculty of Dental Medicine, Lebanese University, Rafic Hariri Campus-Hadath, Beirut, \\ Lebanon \\ ${ }^{4}$ Department of Medical Biotechnologies, Unit of Prosthodontics, University of Siena, Viale Bracci 16, Siena, Italy \\ Corresponding author, Crystal MARRUGANTI; E-mail: marruganti@gmail.com
}

The aim is to evaluate the influence of remaining tooth substance and post-endodontic restoration on fracture strength of endodontically treated maxillary incisors. 150 maxillary central incisors were divided into three groups, Group 0, intact teeth; Group 1, removal of distal wall; Group 2, removal of mesial and distal walls, and further into two subgroups $\mathrm{A}_{0}, \mathrm{~A}_{1}, \mathrm{~A}_{2}$ and $\mathrm{B}_{0}, \mathrm{~B}_{1}, \mathrm{~B}_{2}$ according to post-endodontic restoration (post/no-post), then loaded to fracture. Interactions among variables and intergroup significance were tested with two-way ANOVA and Kruskal Wallis's tests $(p \leq 0.05)$. Tukey's test was applied for multiple comparisons. Statistically significant differences were found between groups $\mathrm{B}_{1}-\mathrm{A}_{1}$, and $\mathrm{B}_{2}-\mathrm{A}_{2}$, but they were not found between $\mathrm{B}_{0}-\mathrm{A}_{0}$. Intragroup analysis showed statistically significant differences in both groups post/no-post with decreasing dental substance. Fiber post placement causes an increase in fracture strength and a reduction of irreparable fractures in endodontically treated maxillary central incisors that lost at least one wall.

Keywords: Maxillary incisors, Post-endodontic restoration, Fiber post, Fracture strength

\section{INTRODUCTION}

The longevity of endodontically treated teeth (ETT) depends on the amount of dental substance and the characteristics of post-endodontic restorations ${ }^{1}$. Over the last twenty years, different types of posts have been introduced for post-endodontic restorations and their clinical use has been the subject of numerous studies. According to literature, the post itself does not strengthen ETT, but provides retention for coronal restorative material in teeth with extensive loss of dental structure ${ }^{2-6)}$. Fiber posts have similar mechanical characteristics to those of dentin, and their failure rarely consists on root fracture, but instead on decementation of the post itself ${ }^{7-9)}$. Another relevant but controversial clinical aspect regarding survival of ETT refers to the influence of the remaining coronal structure. Different authors found a reduction of failures of post-endodontic restorations with the increase of residual dentin height, because the remaining dental substance added retention to the restoration itself ${ }^{10,11}$. The decisionmaking process for post placement is variable between anterior and posterior teeth because occlusal loads are distributed differently in the dental arch: restorations placed in incisors or canines have a failure rate about three times higher than that of restorations placed in premolars or molars ${ }^{12}$. In posterior teeth chewing load direction is mainly axial; in the anterior area it is mostly

Color figures can be viewed in the online issue, which is available at J-STAGE.

Received Jun 8, 2020: Accepted Aug 18, 2020

doi:10.4012/dmj.2020-220 JOI JST.JSTAGE/dmj/2020-220 transversal and related to the bucco-lingual inclination of teeth. Chewing forces can flex teeth to a few degrees and cause elastic deformation, whereas continuous loads can cause permanent plastic deformation, especially in restored teeth, leading to cracks and micro-fractures ${ }^{13)}$. Failures of post-endodontic restorations in anterior teeth have been related to endodontic access cavity configurations $^{14,15)}$, class III $^{14,16)}$ and class IV cavities $^{17)}$, cervical lesions ${ }^{18)}$ or completely decoronated teeth ${ }^{19}$. Many studies investigated the effect of post placement in anterior ETT with class III cavities; they showed that post placement produced no additional benefit in neither fracture strength nor failure pattern ${ }^{16,20)}$. These studies simulated the carious process by only removing $1 / 4$ of the mesio-distal dimension ${ }^{16,20-22)}$. Conversely, in ordinary clinical conditions, endodontic treatment caused by carious lesions is deemed necessary when the cavity invades the pulp chamber, thus significantly reducing the amount of residual coronal substance.

Therefore, the novelty introduced by the present experimental ex vivo model regards the simulation of the class III carious process invading the pulp chamber and leading to the endodontic treatment.

The purpose of this ex vivo study was to evaluate the influence of remaining tooth substance and post endodontic restoration on fracture strength of endodontically treated maxillary central incisors. The null hypothesis tested $\left(\mathrm{H}_{0}\right)$ is that there were no statistically significant differences in fracture resistance between endodontically treated maxillary incisors 
with different amount of residual tooth substance and restored with or without fiberglass posts.

\section{MATERIALS AND METHODS}

\section{Samples selection and preparation}

After local ethics committee approval (protocol number: 17246), patients undergoing tooth extraction in the Oral Surgery, Orthodontics and Periodontology Departments of the University of Siena were screened for inclusion in the study. Among these samples, one hundred-fifty intact upper central incisors with fully formed root apexes were included in the study after informed consent. Each tooth was carefully cleaned from periodontal tissue and plaque using a manual scaler (Hu Friedy, Chicago, IL, USA), and examined to exclude the presence of caries, fractures, cracks or restorations, which would have led to the exclusion from the study. Each sample was placed in a numbered container containing $0.9 \%$ saline solution and stored at $37^{\circ} \mathrm{C}$ until use to prevent dehydration. Bucco-lingual and mesio-distal dimensions of each crown as well as root lengths were recorded with a digital caliper (Digimatic 500, Mitutoyo, Kanagawa, Japan), in order to homogeneously divide teeth into three groups: Group 0 (control, $n=50$ ), intact teeth; Group $1 \quad(n=50)$, removal of distal wall; Group $2(n=50)$, removal of mesial and distal walls. Teeth with similar bucco-lingual (BL) and mesio-distal (MD) CEJ dimensions and similar root length were selected, in order not to affect the results of the study.

Each group was further divided into two subgroups $(n=25)$ : subgroups $\mathrm{A}_{0}, \mathrm{~A}_{1}$ and $\mathrm{A}_{2}$ were restored without the post; subgroups $\mathrm{B}_{0}, \mathrm{~B}_{1}$ and $\mathrm{B}_{2}$ were prepared for glass fiber post placement (Fig. 1) (X-postTM \#1; Dentsply DeTrey $^{\circledR}$, Konstanz, Germany). Endodontic access cavity was performed according to the current guidelines; cavities of roughly triangular shape were obtained, thus reflecting the anatomy of pulp chamber ${ }^{23,24)}$. In samples of groups 1 and 2, the distal wall and the mesial and distal walls respectively were removed, simulating Class III G. V. Black cavities. Cavities size involved 1/3 of the cervico-incisal dimension until $2 \mathrm{~mm}$ from the CEJ, and $1 / 3$ of the mesio-distal dimension stopping at the pulp chamber wall (Fig. 2). Removal of dental tissue was performed using a diamond bur (No.\#12 Coltene, Whaladent, Altststten, Switzerland) under water cooling in multiple operative steps, checking the amount of dental tissue removed for each tooth with a calibrated periodontal probe. Ultrasonic tips and Arkansas stones (Komet, Milan, Italy) were used for the finishing and polishing phase.

\section{Endodontic treatment}

Root canal patency was checked for each tooth using a K\#10 file. Each tooth was placed in a customized silicon mold (Elite HD putty, Zhermack, Badia Polesine, Italy) and chemo-mechanical preparation was performed by a single operator for all samples using reciprocating files (Reciproc blue, R25, VDW, Munich, Germany) to the working length according to manufacturer's instructions.

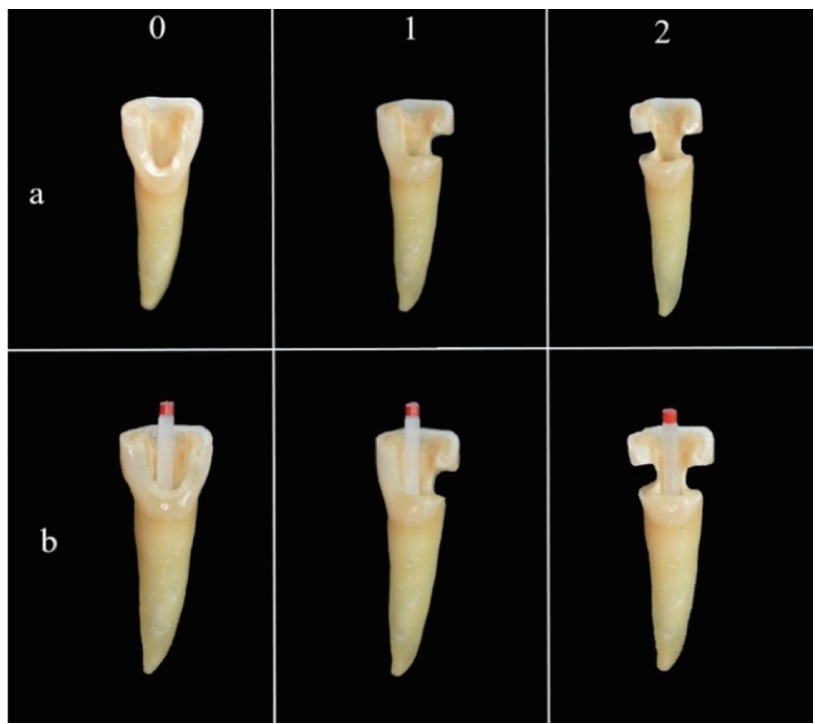

Fig. 1 Distribution of test groups according to remaining tooth substance: 0 (intact teeth), 1 (one wall lost) and 2 (two walls lost); subgroups according to type of restoration: a (restoration with no post) and $b$ (restoration with glass fiber post).

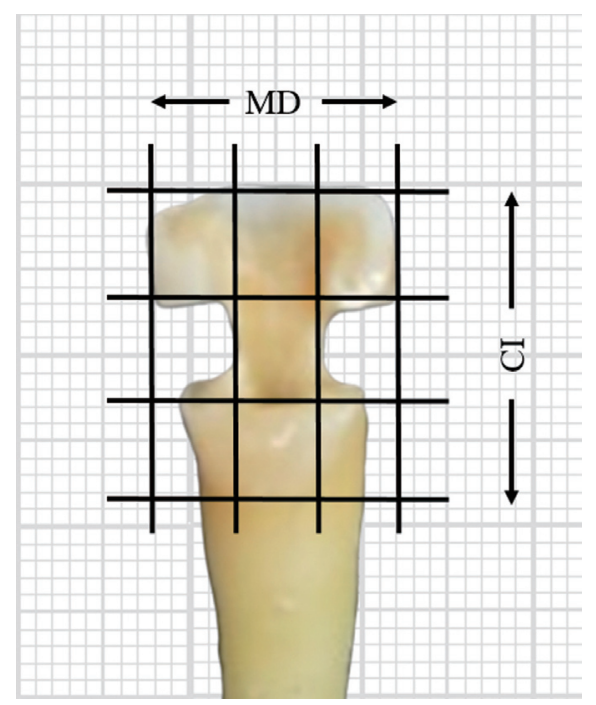

Fig. 2 Mesio-distal (MD) and cervico-incisal (CI) dimensions of each tooth were divided into three equal parts in order to standardize the operative procedures for class III cavities realization.

Mechanical preparation was alternated with irrigation of $5 \%$ sodium hypochlorite solution (Niclor 5, Ogna Lab, Muggiò, Italy). Final flush was carried out with $2 \mathrm{~mL}$ of 17\% EDTA (Ogna Lab) for $2 \mathrm{~min}$, followed by a final wash of $2.5 \mathrm{~mL}$ of $5 \% \mathrm{NaOCl}$ for $5 \mathrm{~min}$, in order to optimize the removal of inorganic and organic components. Canals were then dried using paper points (Reciproc blue R25 paper points, VDW). A veil of sealer (AH Plus, Dentsply, Roma, Italy) was placed on the walls of root canals with 
a paper point. Afterward root canals were filled using the continuous wave of condensation technique. Obturation with gutta-percha was performed using a Reciproc blue R25 master cone and the BeeFill 2 in 1 device (VDW) with a small heat carrier (\#40 tip size and 0.03 taper) following the manufacturer's instructions. After the down-packing phase, the back-filling was performed with the same device and manual compaction using endodontic pluggers (Machtou 1-2 and 3-4, Dentsply Sirona, York, PA, USA). after endodontic treatment all test teeth were restored.

\section{Post-endodontic restoration}

Before starting the adhesive procedures, every access cavity was thoroughly cleaned using a sealer remover (AH Plus Cleaner, Dentsply). In subgroups 0b, $1 \mathrm{~b}$ and $2 \mathrm{~b}$ post endodontic restoration was performed using a post (X-postTM \#1,Dentsply DeTrey ${ }^{\circledR}$ ) for each sample. Post-space was prepared using a drill for post space (DT Universal drill, Dentsply Sirona, Konstanz, Germany) at 1,000-2,000 rpm speed rinsing with water and completed using a dedicated drill for post-pace of the same size of the selected post maintaining an apical seal of at least 5 $\mathrm{mm}$. Canals were then dried with paper points.

Etching was performed (DeTrey Conditioner, Dentsply Sirona) for $15 \mathrm{~s}$, rinsed for $15 \mathrm{~s}$ and dried for 15 s. One to two drops of a universal adhesive (Prime\&Bond Active Universal Adhesive, Dentsply Sirona) were mixed with an equal number of drops of Self-Cure Activator for $2 \mathrm{~s}$ with a clean brush tip. Adhesive was applied to cavity surfaces and left undisturbed for $20 \mathrm{~s}$. Paper points were used to remove surplus from the canal and adhesive mix was gently dried for $5 \mathrm{~s}$ with a moderate air flow from an air-water syringe. Adhesive mix was applied to the post and air dried. Resin cement (Core-X flow, Dentsply De'Trey ${ }^{\circledR}$ ) was immediately placed onto the post surface and to the orifice of the post hole preparation and stabilized within $20 \mathrm{~s}$. Light curing was performed for 40 $\mathrm{s}$ with an irradiance of $750 \mathrm{~mW} / \mathrm{cm}^{2}$ with an orientation parallel to the longitudinal axis of the post.

Mesial and distal walls (groups 1 and 2) were previously restored using resin composites (Ceram-X Duo E2, Dentsply Sirona).

In subgroups $0 \mathrm{a}, 1 \mathrm{a}$ and $2 \mathrm{a}$ no posts were used and Core-X Flow (Dentsply DeTrey ${ }^{\circledR}$ ) was used as core material.

\section{Fracture strength test}

Each tooth was positioned in an aluminum cylinder and embedded in a block of self-curing resin (Gnathus cold self-curing acrylic resin, Zhermak) with the long axis perpendicular to the base of the block with a parallelometer, leaving the roots exposed $2 \mathrm{~mm}$ apically from the CEJ as in a previous study (Fig. 3a) ${ }^{25)}$. To dissipate the heat develeped from the polymerization reaction of the resin, crowns were continuously cooled with an abundant jet of water. A universal loading machine (Triaxal Tester T400 Digital, Controls, Cernusco, Italy) was used. Each specimen was inserted into the holding device with an inclination of $135^{\circ}$ in

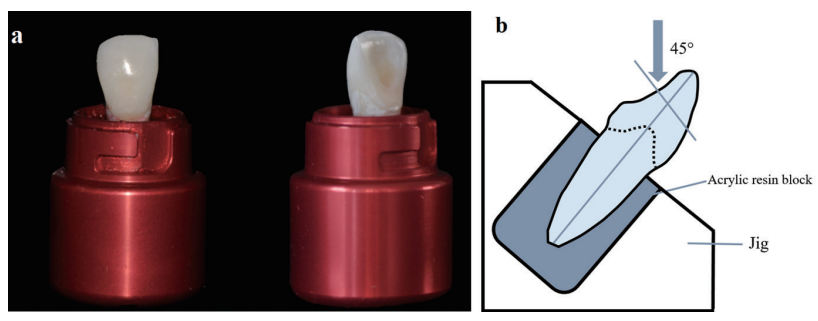

Fig. 3 Samples embeeded in aluminum stubs (a) and positioned for the test (b).

relation to the horizontal plane ${ }^{26)}$. A controlled load was applied with a stainless steel rod with a tip diameter of $2 \mathrm{~mm}$. Pressure of the rod tip was applied $2 \mathrm{~mm}$ below the incisal edge (Fig. 3b). The load was applied at a crosshead speed of $1 \mathrm{~mm} / \mathrm{min}$. All samples were loaded until failure occurred, and the maximum breaking load was recorded in Newton (N). After fracture test, each sample was observed under a stereomicroscope (SZR-10, Optika, Ponetranica, Italy) at $80 \times$ to evaluate the type of fracture. Fractures were highlighted by using an aqueous methylene blue solution (1\%) and dived in: favorable (F), when involving the coronal portion without crossing the CEJ; unfavorable (UF), when involving the root.

\section{Statistical analysis}

Quantitative variables were expressed as mean and standard deviation. Normality distribution of data was proved according to Shapiro-Wilks's test. The homogeneity of variances was carried out by the Levene's test. Two-way ANOVA test was used to detect the influence of the two independent variables (residual crowns structure and presence/absence of fiber post) on the dependent variable (fracture resistance). The nonparametric Kruskal-Wallis's test was used to detect significance between groups. Post-hoc Tukey's test was applied for multiple comparisons. All statistics were performed using Minitab 19 software; level of significance was set at $\alpha=0.05$ for all tests.

\section{RESULTS}

Specimens dimensions for each subgroup and data collected are listed in Tables 1 and 2, respectively. The presence of the post significantly increased fracture resistance in teeth that have lost one $(p=0.001)$ or two walls $(p<0.001)$, while no statistically significant differences were observed in fracture resistance between intact teeth with and without the fiber post $(p=0.244$, Table 3, Fig. 4). Statistically significant differences were also detected between the three subgroups $\mathrm{A}_{0}, \mathrm{~A}_{1}$ and $\mathrm{A}_{2}$ for teeth with decreasing amount of dental substance restored without fiber post, and between the three subgroups $\mathrm{B}_{0}, \mathrm{~B}_{1}$ and $\mathrm{B}_{2}(p<0.05)$ restored with fiber post (Table 3 ). Figure 4 shows the interaction between mean fracture strength and residual crown structure. In particular, the reduction of mean fracture strength values was bigger when shifting from loss of one to 
Table 1 Teeth dimensions (mesio-distal, bucco-lingual and root length) values for each subgroup

\begin{tabular}{|c|c|c|}
\hline Groups & Teeth dimensions & Mean \pm SD $(\mathrm{mm})$ \\
\hline A0 & $\begin{array}{l}\mathrm{MD}^{\S} \\
\mathrm{BL}^{\S} \\
\text { Root length }\end{array}$ & $\begin{array}{r}6.96 \pm 0.67 \\
6.50 \pm 0.56 \\
12.04 \pm 1.01\end{array}$ \\
\hline $\mathrm{A} 1$ & $\begin{array}{l}\text { MD } \\
\text { BL } \\
\text { Root length }\end{array}$ & $\begin{array}{r}6.77 \pm 0.89 \\
6.12 \pm 0.68 \\
11.98 \pm 0.78\end{array}$ \\
\hline $\mathrm{A} 2$ & $\begin{array}{l}\mathrm{MD} \\
\mathrm{BL} \\
\text { Root length }\end{array}$ & $\begin{array}{r}6.66 \pm 0.75 \\
6.03 \pm 0.48 \\
11.75 \pm 1.03\end{array}$ \\
\hline B0 & $\begin{array}{l}\text { MD } \\
\text { BL } \\
\text { Root length }\end{array}$ & $\begin{array}{r}6.58 \pm 0.97 \\
6.37 \pm 0.46 \\
11.45 \pm 0.81\end{array}$ \\
\hline B1 & $\begin{array}{l}\text { MD } \\
\text { BL } \\
\text { Root length }\end{array}$ & $\begin{array}{r}6.59 \pm 0.55 \\
6.21 \pm 0.49 \\
12.11 \pm 0.45\end{array}$ \\
\hline $\mathrm{B} 2$ & $\begin{array}{l}\text { MD } \\
\text { BL } \\
\text { Root length }\end{array}$ & $\begin{array}{r}7.02 \pm 0.37 \\
6.68 \pm 0.66 \\
12.34 \pm 0.92\end{array}$ \\
\hline
\end{tabular}

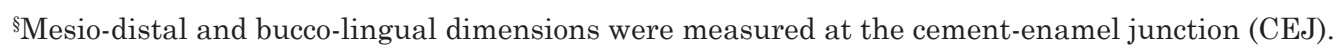

Table 2 Descriptive statistics results for each group

\begin{tabular}{llcccccc}
\hline & $\mathrm{N}$ & Mean(SD) & Min & Q1 & Median & Q3 & Max \\
\hline $\mathrm{A}_{0}$ & 25 & $500.90(24.28)$ & 450.90 & 488.74 & 499.22 & 511.61 & 588.23 \\
$\mathrm{~B}_{0}$ & 25 & $503.21(24.13)$ & 435.12 & 492.96 & 505.32 & 520.70 & 538.12 \\
$\mathrm{~A}_{1}$ & 25 & $432.80(37.25)$ & 361.20 & 415.79 & 443.98 & 461.08 & 478.73 \\
$\mathrm{~B}_{1}$ & 25 & $473.41(30.54)$ & 425.41 & 451.90 & 468.36 & 496.46 & 537.13 \\
$\mathrm{~A}_{2}$ & 25 & $118.01(31.30)$ & 76.51 & 94.33 & 113.67 & 139.29 & 198.72 \\
$\mathrm{~B}_{2}$ & 25 & $307.18(31.25)$ & 251.99 & 293.24 & 315.27 & 328.26 & 352.98 \\
\hline
\end{tabular}

Table 3 The difference between each couple of groups

\begin{tabular}{ccccc}
\hline & post & walls lost & Mean (SD) & $p<0.05$ \\
\hline $\mathrm{A}_{0}$ & - & - & $500.89(24.27)$ & $\alpha$ \\
$\mathrm{B}_{0}$ & + & - & $503.21(24.13)$ & $\beta$ \\
$\mathrm{A}_{1}$ & - & 1 & $432.80(37.24)$ & $\alpha, \mathrm{a}$ \\
$\mathrm{B}_{1}$ & + & 1 & $473.40(30.54)$ & $\beta, \mathrm{a}$ \\
$\mathrm{A}_{2}$ & - & 2 & $118.01(31.30)$ & $\alpha, \mathrm{b}$ \\
$\mathrm{B}_{2}$ & + & 2 & $307.17(41.25)$ & $\beta, \mathrm{b}$ \\
\hline
\end{tabular}

Same letters indicate significance between the two groups $(a, b, \alpha, \beta)$.

loss of two walls in teeth restored without the fiber post. Fracture strength decreased to different amounts moving on from "yes post" to "no post" in the 3 groups considered (intact tooth, one wall loss, two wall loss).
The three couple of points followed the same trend in the interaction graph but the distance between them increased as more walls were removed; in particular, this distance increased drastically in teeth with loss of 


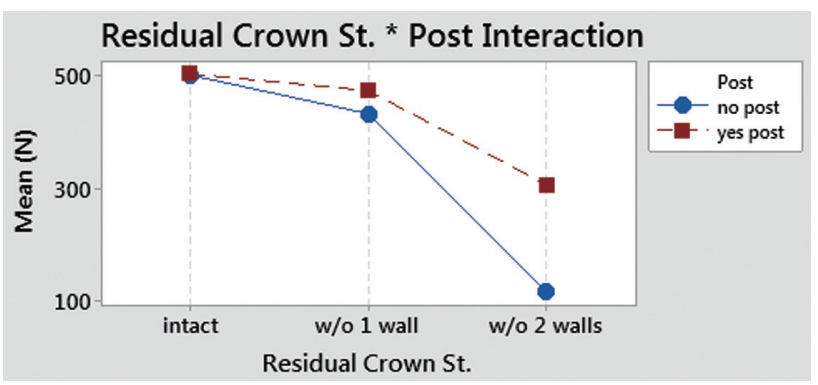

Fig. 4 Mean fracture strength decreased with the decrease of residual coronal structure differently in the two post-endodontic restorations ("yes post" vs "no post").

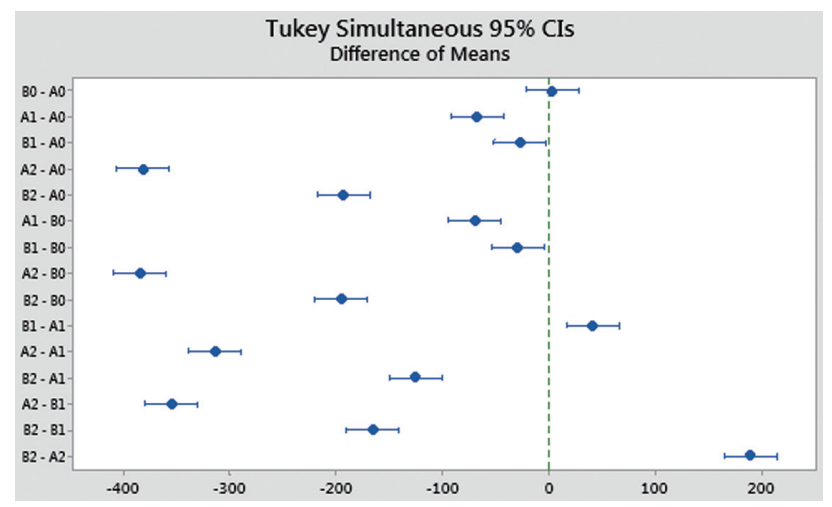

Fig. 5 Multiple comparisons among group couples. If an interval does not contain zero, the corresponding means are significantly different.

Incidence of fracture patterns

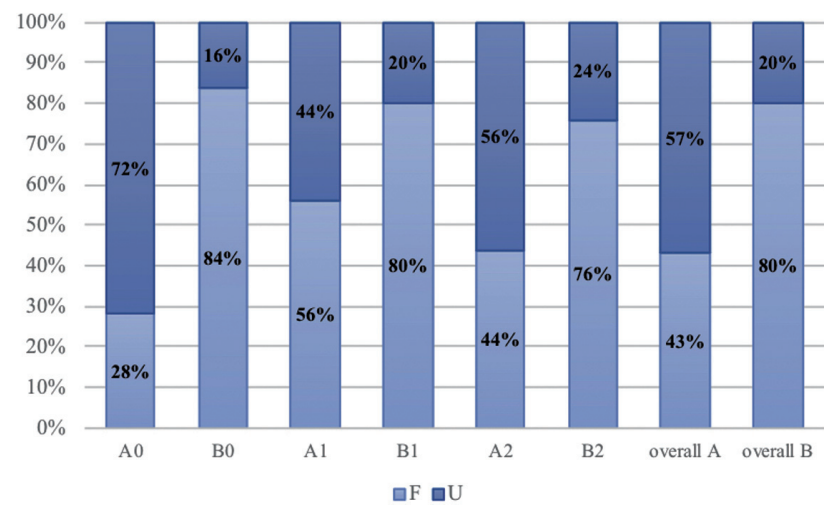

Fig. 6 Incidence of favorable (F) and unfavorable (U) fractures for each group.

two walls. The graph therefore suggested that the two variables, individually, contribute to fracture resistance: the way the fracture resistance ranged between the 3 groups depended on the presence or absence of the post and, in turn, the way fracture resistance ranged in absence or presence of the posts depended on residual crown structure. Comparisons among different couples of groups are represented in Fig. 5. Occurrence frequency of each failure pattern was detected and calculated as percentage; irrespective of the amount of residual dental substance, the insertion of the post increased the percentage of favorable failure pattern and reduced the number of irreparable fractures (Fig. 6).

\section{DISCUSSION}

This ex-vivo study assessed the association between the presence/absence of post and core systems in anterior ETT with different levels of coronal structure damage (from the intact tooth to the tooth with loss of the proximal walls).

The current study showed a statistically significant correlation between fracture resistance of endodontically treated maxillary central incisors restored with and without fiberglass posts and the number of residual coronal walls; therefore, the null hypothesis $\left(\mathrm{H}_{0}\right)$ was rejected. In fact, fracture strength decreased significantly $(p<0.05)$ with the reduction of residual coronal structure both in presence and absence of the intraradicular post. Furthermore, the presence of the fiber post significantly increased $(p<0.05)$ the fracture resistance of teeth that lost one wall, and even more in teeth that lost two coronal walls.

These results are in disagreement with previous studies showing that post placement in anterior ETT with class III cavities produced no additional benefit neither in fracture strength nor in failure pattern ${ }^{16,20)}$. This discrepancy in results is probably due to methodological differences: in the present study, traditional and noncontracted endodontic access cavities were performed. The authors wanted the study to reflect daily clinical dental practice at best; practitioners more often perform traditional endodontic access cavities because, although minimally invasive cavities save more healthy dental tissue, they could adversely affect the subsequent procedures of the root canal treatment, making it more difficult and less predictable. Moreover, class III cavities were realized extending until the pulp chamber wall and removing all the dental tissue from palatal to vestibular surface, in order to simulate the clinical condition of a carious process invading the pulp chamber making the endodontic treatment necessary. Each class III cavity was carried out involving $1 / 3$ of the cervico-incisal dimension and $1 / 3$ of the mesio-distal dimension, unlike in previous studies which involved only $1 / 4$ of the mesiodistal dimension ${ }^{16,20,22,27)}$.

Moreover, some previous studies investigating the bond strength of maxillary incisors, performed a periodontal ligament simulation with the aid of a cushion material ${ }^{16,18,20,22)}$, as suggested by Soares et $a l .{ }^{28)}$ and Sterzenbach et $a l .{ }^{29)}$ in order to increase tooth mobility during in vitro studies. In this study, no simulation of the periodontal ligament was performed; in fact, a recent study by Marchionatti et al. ${ }^{30)}$ showed that the simulation of the periodontal ligament using elastomeric materials does not affect the bond strength and the fracture resistance of teeth restored with fiber 
posts and composite cores, and therefore it may not be necessary to perform periodontal ligament simulations in experimental conditions of fracture test studies.

Due to their anatomical variability, aging and morphological alterations, samples standardization is one of the major challenges of ex vivo studies on extracted human teeth. These morphological alterations mainly involve the coronal portion of teeth due to acid erosions, abrasions and fatigue cracks. In order to standardize the experimental procedure, only central maxillary incisors with similar MD and $\mathrm{BL}$ dimensions at the CEJ and similar root length were included in the present study, as shown in Table 1.

Moreover, post diameter is another conflicting issue in literature. In this study, post diameter $(1.35 \mathrm{~mm})$ did not exceed $1 / 3$ of the root diameter at the CEJ in accordance with previous studies ${ }^{31,32)}$; however, other studies achieved better results with less-conservative post-diameters ${ }^{33,34)}$. The post was placed as deep as possible in the canal without damaging the apical seal $^{35)}$.

According to the results of this study, the authors suggested that the use of fiber post does not strengthen ETT that have lost extensive dental structure; the reduction of failures of post-endodontic restorations with the use of a post-and-core system is probably due to a better retention of the restoration, which causes less failure of the post-endodontic restoration itself ${ }^{2-4)}$. In a review of 2016, authors concluded that an intraradicular retention would be advisable in posterior teeth with less than 50\% of residual coronal structure, when coronal coverage was provided; when no cusp-protection was supplied, even premolars with substantial amount of residual coronal structure could benefit from post placement $^{36)}$.

Indications regarding the need of post insertion for anterior EET remain conflicting. Restoration of anterior ETT with confined tissue loss was demonstrated to be successfully performed by just direct composite restoration ${ }^{3)}$; nevertheless, another study indicated that the type of restoration should be customized according to anatomical limitations, and additional retention could be performed in anterior teeth with small pulp chamber size and thin residual coronal walls ${ }^{5}$.

Although a lower fracture resistance was recorded for specimens restored without fiber post, it does not mean that the fiber post is necessary in all clinical conditions. The incisal load in anterior area is about $200 \mathrm{~N}$, which is lower than the failure load of teeth with one class III cavity and no fiber posts $(432.8 \pm 37.4$ $\mathrm{N})$ detected in this study. In these conditions direct composite restorations with no post insertion would be a suitable clinical choice, being less expensive and invasive. Conversely, anterior teeth with two class III restorations $(118.01 \pm 31.3 \mathrm{~N})$ restored with no fiber posts would not resist to normal occlusal forces.

An additional effect of post placement was highlighted also for failure patterns for all defect sizes; in all groups restored without the post-and-core system, unfavorable failure pattern occurred more frequently than favorable failure pattern (except for group 1a); on the other hand, in groups restored with fiber post a higher percentage of favorable fracture pattern was recorded. The group consisting in intact anterior ETT restored with no fiber post obtained the highest percentage of unfavorable fractures. As showed in a previous study, the fiber post distributes stresses in the external surface of the coronal root third. Moreover, the presence of dentinal coronal walls may influence the stress distribution, and the presence of a fiber post might be relevant for the failure mode $^{16)}$. This condition is maybe due to the fact that when intensive dental substance loss happens, stresses will concentrate in the cervical region and cause favorable failure patterns; however, with the increase of remaining coronal walls, stresses will be increasingly transmitted to the apical area causing irreparable failures.

The current study presents some limitations. In fact, experimental load is a controversial topic in literature $^{37,38)}$. In this study, a unidirectional load was applied to upper central incisors at an angle of $135^{\circ}$ from the longitudinal axis, considering both the mean values of the interincisal angle and the incisal guide ${ }^{2)}$. Conversely, in physiological clinical conditions teeth are subjected to a dynamic load, so either a continuous load in maximum intercuspation and a cyclic load during chewing ${ }^{39}$. Therefore, mechanical and restorative clinical conditions cannot be identically simulated in ex vivo studies.

\section{CONCLUSION}

Within the limitations of the present study, it was possible to conclude that the presence of fiberglass posts increases the fracture strength of endodontically treated maxillary central incisors that lost at least one wall. Moreover, post-endodontic restorations without fiber post placement increase the likelihood of irreparable fractures in endodontically treated maxillary central incisors. Further experimental studies including different loading conditions and different defect sizes and configurations are necessary to mimic intraoral conditions.

\section{ACKNOWLEDGMENTS}

The authors deny any conflict of interest related to this study. This research did not receive any specific grants from funding agencies in the public, commercial, or notfor-profit sectors.

\section{REFERENCES}

1) Fernandes AS, Dessai GS. Factors affecting the fracture resistance of post- core reconstructed teeth: a review. Int $\mathrm{J}$ Prosthodont 2001; 14: 355-363

2) Guzy GE, Nicholls JI. In vitro comparison of intact endodontically treated teeth with and without endo-post reinforcement. J Prosthet Dent 1979; 42: 39-44.

3) Morgano SM. Restoration of pulpless teeth: application of traditional principles in present and future contexts. $J$ Prosthet Dent 1996; 75: 375-380. 
4) Heydecke G, Butz F, Strub JR. Fracture strength and survival rate of endodontically treated maxillary incisors with approximal cavities after restoration with different post and core systems: an in-vitro study. J Dent 2001; 29: 427433.

5) Schwartz RS, Robbins JW. Post placement and restoration of endodontically treated teeth: a literature review. J Endod 2004; 30: 289-301.

6) Salvi GE, Siegrist Guldener BE, Amstad T, Joss A, Lang NP. Clinical evaluation of root filled teeth restored with or without post-and-core systems in a specialist practice setting. Int Endod J 2007; 40: 209-215.

7) Dietschi D, Duc O, Krejci I, Sadan A. Biomechanical considerations for the restoration of endodontically treated teeth: a systematic review of the literature. Part II (Evaluation of fatigue behaviour, interfaces, and in vivo studies). Quintessence Int 2008; 39: 117-129.

8) Cagidiaco MC, Goracci C, Garcia-Godoy F, Ferrari M. Clinical studies of fiber posts: a literature review. Int J Prosthodont 2008; 21: 328-336.

9) Cagidiaco MC, Goracci C, Garcia-Godoy F, Ferrari M. Clinical trials of fiber posts: a literature review. In: Ferrari M, Breschi L, Grandini S (eds). Fiber posts and endodontically treated teeth: a compendium of scientific and clinical perspectives. Wendywood: Modern Dentistry Media 2008: 149-163.

10) Fokkinga Wietske A, Kreulen Cees M, Bronkhorst Ewald M, Creugers Nico HJ. Up to 17-year controlled clinical study on post-and-cores and covering crowns. J Dent 2007; 35: 778786.

11) Cagidiaco MC, Radovic I, Simonetti M, Tay F, Ferrari M. Clinical performance of fiber post restorations in endodontically treated teeth: 2 -year results. Int J Prosthodont 2007; 20: 293-298.

12) Naumann M, Blankenstein F, Dietrich T. Survival of glass fibre reinforced composite post restorations after 2 years-an observational clinical study. J Dent 2005; 33: 305-312.

13) Vârlan C, Dimitriu B, Vârlan V, Bodnar D, Suciu I. Current opinions concerning the restoration of endodontically treated teeth: basic principles. J Med Life 2009; 2: 165-172.

14) Magne P, Tan DT. Incisor compliance following operative procedures: a rapid 3-D finite element analysis using microCT data. J Adhes Dent 2008; 10: 49-56.

15) D'Arcangelo C, De Angelis F, Vadini M, D'Amario M, Caputi S. Fracture resistance and deflection of pulpless anterior teeth restored with composite or porcelain veneers. J Endod 2010; 36: 153-156.

16) Abduljawad M, Samran A, Kadour J, Karzoun W, Kern M. Effect of fiber posts on the fracture resistance of maxillary central incisors with class III restorations: an in vitro study. J Prosthet Dent 2016; 118: 55-60.

17) Vadini M, De Angelis F, D’Amario M, Marzo G, Baldi M, D'Arcangelo C. Conservative restorations of endodontically compromised anterior teeth in paediatric patients: physical and mechanical considerations. Eur J Paediatr Dent 2012; 13: 263-267.

18) Abduljawad M, Samran A, Kadour J, Al-Afandi M, Ghazal M, Kern M. Effect of fiber posts on the fracture resistance of endodontically treated anterior teeth with cervical cavities: an in vitro study. J Prosthet Dent 2016; 116: 80-84.

19) Ramirez-Sebastia A, Bortolotto T, Cattani-Lorente M, Giner L, Roig M, Krejci I. Adhesive restoration of anterior endodontically treated teeth: influence of post length on fracture strength. Clin Oral Investig 2014; 18: 545-554.

20) von Stein-Lausnitz M, Bruhnke M, Rosentritt M, Sterzenbach G, Bitter K, Frankenberger R, et al. Direct restoration of endodontically treated maxillary central incisors: post or no post at all? Clin Oral Investig 2019; 23: 381-389.

21) Sorrentino R, Monticelli F, Goracci C, Zarone F, Tay FR,
Garcia-Godoy F, et al. Effect of residual coronal structure on resistance of teeth restored with posts. G Ital Endod 2012; 26; $13-21$.

22) von Stein-Lausnitz M, Mehnert A, Bruhnke M, Sterzenbach G, Rosentritt M, Spies BC, et al. Direct or indirect restoration of endodontically treated maxillary central incisors with class III defects? Composite vs veneer or crown restoration. J Adhes Dent 2018; 20: 519-526.

23) Inlge JI. Endodontic cavity preparation. In: Ingle J, Tamber J, editors. Endodontics, 3rd ed. Philadelphia: Lea \& Febiger, 1985; $102-167$.

24) Castellucci A. In: Castellucci A, editor. Endodonzia. Bologna: Edizioni Martina; 2018. p. 52-64.

25) Krishan R, Paquè F, Ossareh A, Kishen A, Dao T, Friedman S. Impact of conservative endodontic cavity on root canal instrumentation efficacy and resistance to fracture assessed in incisors premolars and molars. J Endod 2014; 40: 11601166.

26) Abdulrahman F, Maged N, Abdulaziz S, Ahlam S, Giraldine A, Ali A. et al. Fracture resistance of endodontically treated anterior teeth restored with different post systems: An in vitro study. Eur Endod J 2018; 3: 174-178.

27) Mangold JT, Kern M. Influence of glass-fiber posts on the fracture resistance and failure pattern of endodontically treated premolars with varying substance loss: an in vitro study. J Prosthet Dent 2011; 105: 387-393.

28) Soares CJ, Pizi EC, Fonseca RB, Martins LR. Influence of root embedment material and periodontal ligament simulation on fracture resistance tests. Braz Oral Res 2005; 19: 11-16.

29) Sterzenbach G, Kalberlah S, Beuer F, Frankenberger R, Naumann M. In-vitro simulation of tooth mobility for static and dynamic load tests: a pilot study. Acta Odontol Scand 2011; 69: 316-318.

30) Marchionatti AM, Wandscher VF, Broch J, Bergoli CD, Maier J, Valandro LF, et al. Influence of periodontal ligament simulation on bond strength and fracture resistance of roots restored with fiber posts. J Appl Oral Sci 2014; 22: 450-458.

31) Tilk MA, Lommel TJ, Gerstein H. A study of mandibular and maxillary root widths to determine dowel size. J Endod 1979; 5: 79-82.

32) Tjan AH, Whang SB. Resistance to root fracture of dowel channels with various thicknesses of buccal dentin walls. J Prosthet Dent 1985; 53: 496-500.

33) Kivanç BH, Alaçam T, Ulusoy OI, Genç O, Görgül G. Fracture resistance of thin-walled roots restored with different post systems. Int Endod J 2009; 42: 997-1003.

34) Du JK, Lin WK, Wang CH, Lee HE, Li HY, Wu JH. FEM analysis of the mandibular first premolar with different post diameters. Odontology 2011; 99: 148-154.

35) Mattison GD, Delivanis PD, Thacker RW, Hassel KJ. Effect of post space preparation on the apical seal. J Prosthet Dent 1984; 51: 785-789.

36) Aurélio IL, Fraga S, Rippe MP, Valandro LF. Are posts necessary for the restoration of root filled teeth with limited tissue loss? A structured review of laboratory and clinical studies. Int Endod J 2016; 49: 827-835.

37) Loney RW, Moulding MB, Ritsco RG. The effect of load angulation on fracture resistance of teeth restored with cast post and cores and crowns. Int J Prosthodont 1995; 8: 247251.

38) Krejci I, Duc O, Dietschi D, de Campos E. Marginal adaptation, retention and fracture resistance of adhesive composite restorations on devital teeth with and without posts. Oper Dent 2003; 28: 127-135.

39) Larson TD. Part two: The restoration of non-vital teeth: structural, biological, and micromechanical issues in maintaining tooth longevity. Northwest Dent 2006; 85: 23$25,27,29-32$. 